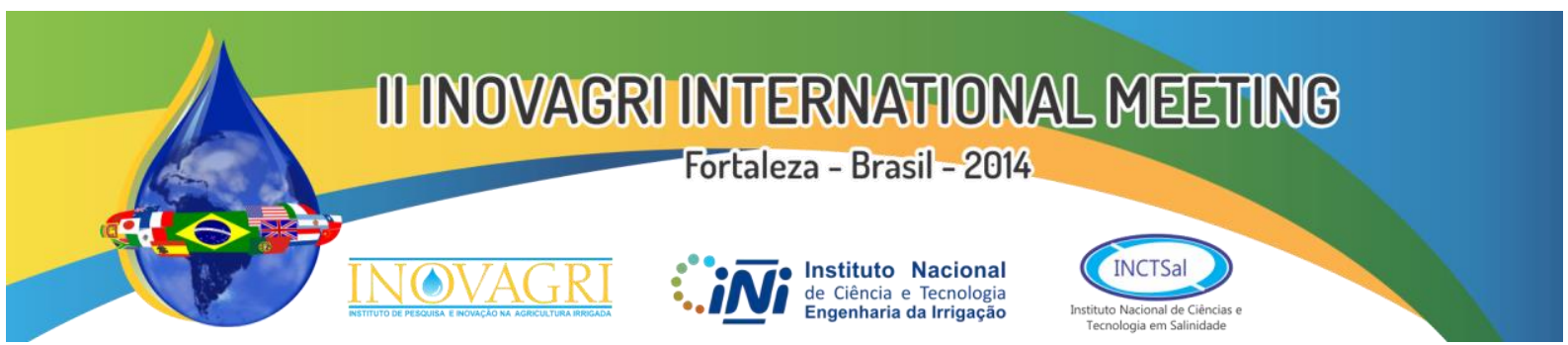

http://dx.doi.org/10.12702/ii.inovagri.2014-a064

\title{
COEFICIENTE DE CULTIVO E LÂMINAS DE IRRIGAÇÃO DO MARACUJAZEIRO AMARELO NAS CONDIÇÕES SEMIÁRIDAS
}

\author{
E. Nogueira ${ }^{1}$; E. R. Gomes ${ }^{2}$; V. F. de Sousa ${ }^{3}$; L. R. A. da Silva ${ }^{4}$; F. Broetto
}

\begin{abstract}
RESUMO: O trabalho teve como objetivo determinar o coeficiente de cultivo do maracujazeiro amarelo, definir lâminas de irrigação capazes de elevar a produtividade da cultura e a qualidade da produção nas condições ambientais da região semiárida do Piauí. O experimento foi realizado na área do Projeto Piloto de Fruticultura Irrigada no município de Santa Rosa, PI. Utilizou-se delineamento experimental blocos ao acaso, com seis tratamentos e quatro repetições. Os tratamentos (lâminas de irrigação) foram definidos em função de percentagens da evapotranspiração de referência (ETo): T1: 25\%; T2: 50\%; T3: 75\%; T4: 100\%; T5: $125 \%$ e T6: $150 \%$. Para o monitoramento da água no perfil do solo utilizou-se tensiômetros. Para determinação do coeficiente de cultivo (kc), utilizou-se o balanço de água no solo com base no tratamento de $100 \%$ reposição de água. Foram avaliadas características morfofisiológicas do maracujazeiro amarelo. A produtividade máxima de $27.052 \mathrm{~kg} \mathrm{ha}^{-1}$ ano $^{-1}$ foi obtida com aplicação da lâmina de irrigação de 763,80 $\mathrm{mm}$. Os valores de peso médio de fruto variou de $0,207 \mathrm{~kg}$ (T6) e $0,159 \mathrm{~kg}$ (T1). O kc médio obtido para a fase vegetativa foi de 0,57 para fase de floração 0,94 e para a fase de frutificação 1,04 . As lâminas de irrigação de maior eficiência compreendem-se no intervalo de 75\% e 100\% ETo.
\end{abstract}

Palavras chave: Passiflora edulis Sims f. flavicarpa, Demanda hídrica, Manejo de água.

\section{CROP COEFFICIENT AND IRRIGATION BLADES OF YELLOW PASSION FRUIT IN SEMI-ARID CONDITIONS}

ABSTRACT: The study aimed to determine the coefficient of the yellow passion fruit cultivation and irrigation set capable of increasing crop productivity and quality of production in the environmental conditions of the semi-arid region of Piauí. The experiment was conducted in the Pilot Project for Fruit Crops Irrigated area in Santa Rosa, PI. We used a randomized block design with six treatments and four replications. Treatments (irrigation) were defined according to percentages of reference evapotranspiration (ETo): T1 25\%, T2: 50\%, T3: 75\%, T4: 100\%; T5: T6 and 125\%: 150\%. For monitoring water in the soil profile was used tensiometers. To determine the crop coefficient $(\mathrm{Kc})$ used the water balance in the soil treatment based on $100 \%$ replacement of water. Morphological and physiological characteristics of yellow passion fruit were evaluated. The maximum yield of $27.052 \mathrm{~kg} \mathrm{ha}^{-1} \mathrm{yr}^{-1}$ was obtained by applying a water depth of $763.80 \mathrm{~mm}$. The values of average fruit weight ranged from $0.207 \mathrm{~kg}$ (T6) and $0.159 \mathrm{~kg}$ (T1). The average kc obtained for the vegetative stage was 0.57 to 0.94 and flowering stage to fruiting phase 1.04. The water depth of greater efficiency comprise in the range of $75 \%$ and $100 \%$ ETo.

Keywords: Passiflora edulis Sims f. flavicarpa, Water demand, Water management.

\section{INTRODUÇÃO}

O maracujazeiro é uma fruteira bastante cultivada no Brasil e de bom retorno econômico para os produtores. O Brasil está inserido dentre os maiores produtores de maracujá do mundo, possuindo uma

\footnotetext{
${ }^{1}$ Mestre em Engenharia Agrícola (Irrigação e Drenagem) pela UFC, Fortaleza-CE. E-mail: eliomar29@ @otmail.com

${ }^{2}$ Doutorando em Agronomia (Irrigação e Drenagem), UNESP/FCA, Campos Botucatu-SP. E-mail: edilsonevj@ hotmail.com

${ }^{3}$ Doutor, Pesquisador da Embrapa Cocais e Bolsista PQ do CNPq, São Luis-Ma

${ }^{4}$ Mestranda em Genética e Melhoramento da Universidade Estadual do Norte Fluminense-UENF-RJ

${ }^{5}$ Prof. Doutor, Instituto de Biociências, Universidade Estadual Paulista/UNESP, Departamento de Química e Bioquímica, Botucatu-SP
}

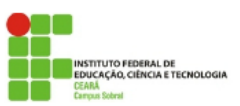


área de 61842 ha, com uma produção de 923035 toneladas e um rendimento médio de $14976 \mathrm{Kg} \mathrm{ha}^{-1}$ até ano de 2012, (AGRIANUAL, 2013). Já o Piauí possui uma área de 42 ha, produção de 479 toneladas e rendimento médio em cerca de $23 \%$ abaixo do nacional, com $11.405 \mathrm{Kg} \mathrm{ha}^{-1}$ (IBGE, 2010). No entanto, o rendimento médio da produção nacional fica em torno de $15 \mathrm{t} \mathrm{ha}^{-1}$, ainda é considerado um valor muito baixo levando em consideração que a cultura tem potencial para produzir até $42 \mathrm{t} \mathrm{ha}^{-1}$ (EMBRAPA, 2010). Assim, o maracujá amarelo tem ocupado um lugar de destaque na fruticultura, mesmo quando comparado a outras frutas tropicais com maior tradição de consumo (MELETTI et al., 2010).

Segundo Freire et al. (2010) a baixa produtividade nacional é resultante da falta de investimento, do baixo emprego de tecnologia de produção e principalmente do cultivo em ambientes com severas restrições hídricas e climáticas, como no Nordeste Brasileiro. Nas últimas décadas, a fruticultura irrigada tem obtido espaço na agricultura brasileira de maneira significativa, alcançando grandes avanços no que diz respeito à economia e eficiência de uso de água aplicada pela irrigação, principalmente, na região Nordeste, onde o cultivo se restringe ao uso da irrigação. O maracujazeiro responde bem à irrigação e torna-se uma prática essencial no sentido de se obter maiores produtividades e melhoramento na qualidade dos frutos (ARAÚJO et al., 2012), porém o momento de aplicação de água depende da fase de crescimento e das condições meteorológicas locais (VIANA et al., 2012). Por outro lado, para a maximização da lucratividade dos sistemas de produção irrigados a quantidade de água a ser aplicada deve estar relacionada também ao requerimento hídrico e ao manejo da cultura (SILVA et al., 2012).

Nas regiões semiáridas a suplementação de água via irrigação é vital para produção de alimentos visto que as precipitações pluviométricas são irregulares e mal distribuídas. Sendo assim, é necessário práticas de manejo de irrigação a fim de garantir a sustentabilidade agrícola. Nesse contexto a determinação da evapotranspiração de culturas (ETc) torna-se de extrema importância podendo ser determinada com precisão a partir dos métodos micrometeorológicos, lisímetros, balanço de água no solo, dentre outros métodos diretos. (BEZERRA et al., 2012). Haja vista que o método do balanço hídrico no solo vem sendo muito utilizado para se estimar a evapotranspiração e a eficiência no uso de água de várias culturas (MOROKE et al., 2011). De acordo com Paes et al. (2012) a evapotranspiração de referência (ETo) pode ser determinada indiretamente por fórmulas empíricas, baseadas em dados meteorológicos. Já a ETc é obtida através do valor da ETo corrigida pelo Kc, teoricamente determinado pela relação ETc/ETo, sendo este dependente do tipo de cultura e do estágio de desenvolvimento. O Kc é a expressão da demanda hídrica da planta, sendo que este não é valor fixo para todas as situações climáticas.

Este trabalho teve como objetivo determinar o coeficiente de cultivo do maracujazeiro amarelo e definir lâminas de irrigação capazes de elevar a produtividade da cultura e a qualidade da produção nas condições ambientais da região semiárida do Piauí.

\section{MATERIAL E MÉTODOS}

\section{Caracterização da área experimental}

O experimento foi realizado em área do Projeto Piloto de Fruticultura Irrigada do Vale do Parnaíba, localizado no município de Santa Rosa do Piaú com latitude e longitude de $06^{\circ} 47^{\prime} 56^{\prime}$ " S e 42 $17^{\prime} 17^{\prime}$, W, respectivamente, com altitude de $187 \mathrm{~m}$, instalado pela Companhia de Desenvolvimento das Bacias dos Vales dos Rios São Francisco e Parnaíba - CODEVASF.

Segundo a classificação de Köppen a região é do tipo BSw'h', o clima é tropical semiárido (quente e seco). A região apresenta temperatura média de $29^{\circ} \mathrm{C}$, umidade relativa média do ar $67 \% \mathrm{e}$ precipitação pluviométrica média de $812 \mathrm{~mm}$, com período chuvoso de novembro a abril.

O solo da área experimental é classificado como Neossolo Litólico Distrófico, de textura areia franca (SANTOS et al., 2006). Para a sua caracterização física, química e hídrica foram coletadas amostras das camadas de 0,00 - 0,20;0,20 - 0,40 e 0,40 - 0,60 m e a curva de retenção de água no solo conforme Van Genuchten (1980).

\section{Delineamento da área experimental e Sistema de irrigação}

O delineamento experimental utilizado foi o de blocos casualizados com seis tratamentos: T1: 25\%; T2: 50\%; T3: 75\%; T4: 100\%; T5: 125\% e T6: 150\% (lâminas de irrigação estimadas a partir de 
percentuais da ETo) com quatro repetições. A irrigação utilizada foi por gotejamento com três gotejadores por planta espaçados de $0,40 \mathrm{~m}$ e $0,20 \mathrm{~m}$ do caule da planta. $\mathrm{O}$ sistema de irrigação apresentavam linhas laterais com mangueiras de polietileno com diâmetro de $16 \mathrm{~mm}$ e gotejadores tipo Katif, com vazão de $4,0 \mathrm{~L} \mathrm{~h}^{-1}$ e pressão de serviço 10 mca.

\section{Plantio e manejo da cultura}

O preparo do solo constou de duas gradagens, com aplicação e incorporação de $2,0 \mathrm{t} \mathrm{ha}^{-1}$ de calcário dolomítico 60 dias antes do transplantio das mudas. As covas foram abertas no espaçamento de 4,0 $\mathrm{m} \times 2,5 \mathrm{~m}$ e nas dimensões de $0,50 \mathrm{~m} \times 0,50 \mathrm{~m} \times 0,50 \mathrm{~m}$. A adubação de fundação foi feita na cova aplicando 20 litros de esterco de curral, $1,0 \mathrm{~kg}$ de $\mathrm{P}_{2} \mathrm{O}_{5}$ (Superfosfato simples) e $50 \mathrm{~g}$ de FTE BR 12 (2,17\% de B, $0,80 \%$ de $\mathrm{Cu}, 3,85 \%$ de Fe, 3,48\% de Mn, $0,13 \%$ de Mo e 9,24\% de Zn). Foi utilizada mudas de maracujazeiro (Passiflora edulis Sims var. flavicarpa Deg.) da variedade amarelo redondo.

Nas adubações de cobertura aplicou-se $320 \mathrm{~kg} \mathrm{ha}^{-1}$ ano ${ }^{-1}$ de uréia e de cloreto de potássio 475 $\mathrm{kg} \mathrm{ano}^{-1}$, conforme recomendação de Haag et al. (1973). O sistema de sustentação das plantas foi feito com espaldeiras verticais, com espaçamento de 4,0 m entre plantas e 2,5 m entre linhas, utilizando-se um fio de arame liso ( $\left.\mathrm{n}^{\circ} 12\right)$, preso e esticado por mourões, a aproximadamente $1,80 \mathrm{~m}$ da superfície do terreno.

\section{Lâminas de irrigação}

Diariamente na estação agrometeorológica automática instalada na área do projeto foram coletados os dados referentes às características climáticas (umidade relativa, temperatura, velocidade e direção do vento, radiação solar e radiação líquida) necessários à estimativa da evapotranspiração de referência (ETo) pelo método de Penman-Monteith, padronizado por Allen et al. (1998).

$\mathrm{Na}$ irrigação localizada, a área molhada é menor que a área total, foi utilizada um coeficiente de redução (Kr), assim, corrigindo a área total (AT) com $10 \mathrm{~m}^{2}(4,0 \mathrm{~m} \times 2,5 \mathrm{~m})$ segundo Vermeiren e Jobling (1997):

O índice de sombreamento foi efetuado através da relação da área sombreada pela planta e a área total ocupada pela mesma planta (AS/AT), sendo que a área sombreada foi efetuada pelo produto do comprimento da planta $(4,0 \mathrm{~m})$ e a largura da copa da planta. $\mathrm{O}$ valor da largura da copa sendo prédeterminada em $0,20 \mathrm{~m} ; 0,30 \mathrm{~m}$ e $0,40 \mathrm{~m}$.

A uniformidade de distribuição foi avaliada pela equação de Christiansen, conforme Bernardo et al. (2009). O coeficiente (CUC) encontrado foi de $91 \%$.

O volume de água (Equação 1) aplicado foi calculado por meio da avaliação de diferentes tratamentos (lâminas de irrigação) estimadas a partir de percentuais da ETo: T1: 25\%; T2: 50\%; T3: 75\%; T4: 100\%; T5: $125 \%$ e T6: $150 \%$.

$$
\mathrm{V}=(\mathrm{ETo} \times \mathrm{P} \times \mathrm{Kr} \times \mathrm{AT}) / \mathrm{Ef}(1)
$$

em que,

$\mathrm{V}$ - Volume de água $(\mathrm{L})$

ETo - Evapotranspiração de referência $\left(\mathrm{mm} \mathrm{dia}^{-1}\right)$;

$\mathrm{P}$ - Percentagem correspondente ao tratamento;

$\mathrm{Kr}$ - Coeficiente de redução de área;

AT - Área total ou área ocupada pela planta $\left(\mathrm{m}^{2}\right)$;

Ef - Eficiência de irrigação $(0,91)$.

Efetuando a conversão do volume de água aplicado (L) por lâmina (mm), conforme equação 2, consequentemente, obteve o tempo de irrigação para cada tratamento.

em que,

$$
\mathrm{L}_{\mathrm{a}}=\mathrm{V} / \mathrm{AT}_{\mathrm{c}}(2)
$$

$\mathrm{L}_{\mathrm{a}}$ - Lâmina aplicada (mm);

V - Volume de água (L);

$\mathrm{AT}_{\mathrm{c}}$ - Área total da planta corrigida $\left(\mathrm{m}^{2}\right)$, pelo $\mathrm{Kr}$. 
Para a estimativa da precipitação efetiva $(\mathrm{mm})$, foi calculada a redução permissível de água disponível do solo, ou seja, $(C C-P M) x z$ que foi tomado como valor limite da Pe e calculada a umidade atual $\left(\mathrm{cm}^{-3} \mathrm{~cm}^{-3}\right)$ no período, na profundidade $(\mathrm{z})$ de $400 \mathrm{~mm}$.

\section{Determinação da umidade e monitoramento de água no solo}

Instalou-se uma bateria com três tensiômetros de punção em todos os tratamentos nas profundidades de $0,10 \mathrm{~m} ; 0,30 \mathrm{~m}$ e $0,50 \mathrm{~m}$, a uma distância de $0,30 \mathrm{~m}$ do caule. Para a determinação do coeficiente de cultivo (Kc) utilizou-se o T4 (100\% ETo) com duas baterias, isto é, seis tensiômetros sendo instalados nas mesmas profundidades, porém, em distâncias de $0,30 \mathrm{~m}$ e $0,60 \mathrm{~m}$ do caule da planta.

Os valores das leituras foram convertidos em potencial matricial de água no solo (- $\left.\Psi_{\mathrm{m}}\right)$ na unidade de $\mathrm{kPa}$ e posteriormente com os parâmetros do modelo descrito por Van Genuchten (1980), foram obtidas conforme Dourado Neto et al. (1995) com o auxílio do software SWRC versão 3.0 (Soil Water Retention Curve), determinou-se os teores de umidade para as camadas de $0,0-0,20 \mathrm{~m} ; 0,20$ $0,40 \mathrm{~m}$ e $0,40-0,60 \mathrm{~m}$.

\section{Determinação da evapotranspiração da cultura e do coeficiente de cultivo (Kc)}

Os dados de tensão de água no solo que foram determinados nos tensiômetros foram utilizados para realizar o balanço de água no solo e estimar a evapotranspiração da cultura (ETc). A equação 3 utilizada foi à seguinte:

$$
\mathrm{ETc}=(\mathrm{I}+\mathrm{Pe})-\mathrm{h}-\mathrm{D}(3)
$$

em que,

I - Lâmina total de irrigação no período (mm);

P - Precipitação efetiva no período (mm);

D - Lâmina de drenagem no período $(\mathrm{mm})$;

$\mathrm{h}$ - Armazenamento de água no período (mm).

O coeficiente de cultivo $(\mathrm{Kc})$ foi determinado pela relação descrita na equação 4 entre a evapotranspiração de cultura e a evapotranspiração de referência, determinados através do balanço hídrico e pela estação meteorológica automática, respectivamente.

$$
\mathrm{Kc}=\frac{\mathrm{ET}_{\mathrm{c}}}{\mathrm{ET}_{\mathrm{o}}}
$$

em que,

kc - Coeficiente da cultura;

ETc - Evapotranspiração da cultura $\left(\mathrm{mm} \mathrm{dia}^{-1}\right)$;

ETo - Evapotranspiração da cultura de referência $\left(\mathrm{mm} \mathrm{dia}^{-1}\right)$.

\section{Características morfofisiológicas e produção avaliadas na planta}

$\mathrm{O}$ número de folhas (unidade) e a área foliar $\left(\mathrm{m}^{2}\right.$ planta $\left.^{-1}\right)$ foram determinados por meio de um medidor de superfície portátil, modelo LI 3000 A. As folhas foram medidas individualmente e os valores armazenados em um leitor digital e que permite medir área foliar no campo sem destruí-las.

O período de colheita durou por volta de 60 dias. Foram avaliados peso médio dos frutos $(\mathrm{kg})$ em uma balança de precisão e depois medidos com um paquímetro digital o diâmetro longitudinal e transversal $(\mathrm{cm})$ do fruto. Foi-se obtida média de produção por hectare para cada tratamento (lâminas de irrigação) ao final da colheita.

\section{RESULTADO E DISCUSSÃO}

\section{Características climáticas no período}

Foram coletados dados diários de variáveis meteorológicas (Tabela 1) que deram subsídios ao cálculo da evapotranspiração de referência (ETo), utilizando o método de Penman-Monteith, padronizado pela FAO. Todos os dados necessários foram registrados pela estação meteorológica automática. 
Tabela 1 - Valores médios mensais de temperatura (T), umidade relativa (UR), velocidade do vento $\left(\mathrm{U}_{2}\right)$, radiação líquida $(\mathrm{Rn})$ e precipitação $(\mathrm{P})$ e evapotranspiração de referência (ETo) total estimada pelo método Penman-Monteith no município de Santa Rosa do Piauí.

\begin{tabular}{lcccccc}
\hline Mês / ano & $\mathrm{T}\left({ }^{\circ} \mathrm{C}\right)$ & $\mathrm{UR}(\%)$ & $\mathrm{U}_{2}\left(\mathrm{~m} \mathrm{~s}^{-1}\right)$ & $\mathrm{Rn}\left(\mathrm{MJ} \mathrm{m}^{-2}\right)$ & $\mathrm{P}(\mathrm{mm})$ & ETo $(\mathrm{mm})$ \\
\hline Setembro/09 & 29,5 & 41,2 & 0,745 & 5,42 & 1,0 & 45,5 \\
Outubro/09 & 28,8 & 57,4 & 0,821 & 4,87 & 51,8 & 71,3 \\
Novembro/09 & 29,0 & 56,3 & 0,834 & 4,99 & 35,4 & 74,4 \\
Dezembro/09 & 27,4 & 70,0 & 0,603 & 4,15 & 60,4 & 57,7 \\
Janeiro/10 & 25,8 & 83,2 & 0,441 & 4,25 & 114,8 & 45,9 \\
Fevereiro/10 & 27,2 & 77,6 & 0,528 & 4,46 & 74,8 & 48,6 \\
Março/10 & 26,5 & 86,0 & 0,217 & 4,26 & 236,4 & 43,4 \\
Abril/10 & 26,4 & 84,5 & 0,400 & 4,09 & 157,1 & 46,5 \\
Maio/10 & 26,4 & 85,2 & 0,381 & 4,17 & 75,0 & 22,1 \\
\hline Total & - & - & - & - & 806,5 & 455,4 \\
\hline
\end{tabular}

Durante o experimento foram registrados $806,50 \mathrm{~mm}$ de precipitação total, valor este considerado como nível mínimo de chuvas (sem aplicação de irrigação) para o desenvolvimento da cultura do maracujazeiro (SANTOS; RESENDE, 2006), isto se a precipitação for uniforme e bem distribuída, porém neste caso as chuvas na região não tiveram este comportamento, havendo muitas oscilações com várias semanas seguidas sem chuvas, característica própria do semiárido.

\section{Lâminas de água e monitoramento da umidade do solo}

O período inicial de 60 DAT foi destinado ao estabelecimento da cultura, portanto, não foram diferenciadas as lâminas de água aplicadas aos tratamentos. A partir dos 61 até os 240 DAT as quantidades d'água foram diferenciadas de acordo com os tratamentos $1,2,3,4,5$ e 6 , respectivamente, $25 \%, 50 \%, 75 \%, 100 \%, 125 \%$ e $150 \%$ da ETo.

A quantidade de água total aplicada na cultura do maracujazeiro amarelo durante os 240 dias foi de $408,25 \mathrm{~mm}, 463,41 \mathrm{~mm} 535,11 \mathrm{~mm}, 609,98 \mathrm{~mm}, 704,71 \mathrm{~mm}$ e $826,02 \mathrm{~mm}$ para os respectivos tratamentos T1, T2, T3, T4, T5 e T6.

Devido à maior concentração de raízes de o maracujazeiro amarelo ocorrer numa camada de 0,00 a $0,40 \mathrm{~m}$ foram avaliados os perfis de umidade do solo nesta camada fazendo comparação com os teores médios de umidade e a CAD a partir dos 61 DAT início das diferenciações de lâminas.

Numa avaliação das lâminas de irrigação aplicadas pelos respectivos tratamentos T1e T2, como observa-se na Figura 1 (i) e (ii) os valores de umidade média foi de $0,1285 \mathrm{~cm}^{-3} \mathrm{~cm}^{-3}$ e $0,1348 \mathrm{~cm}^{-3}$ $\mathrm{cm}^{-3}$ apresentando entre todos os tratamentos as maiores distâncias da (CAD). Para os tratamentos T3 e T4 como mostra na Figura 1 (iii) e (iv), os respectivos valores médios de umidade do solo foram de $0,1370 \mathrm{~cm}^{-3} \mathrm{~cm}^{-3}$ e $0,1378 \mathrm{~cm}^{-3} \mathrm{~cm}^{-3}$ apresentando valores mais próximos da CAD que o T1 e T2. O tratamento T5 na Figura $1(\mathrm{v})$ apresenta valor médio de umidade $0,1408 \mathrm{~cm}^{-3} \mathrm{~cm}^{-3}$ nivelado à CAD. E conforme apresentado na Figura 1 (vi) o valor médio de umidade do solo $\left(0,1518 \mathrm{~cm}^{-3} \mathrm{~cm}^{-3}\right)$ com a aplicação de $150 \%$ da ETo (tratamento T6) foi superior as médias dos demais tratamentos.

Diante dessas variações de umidade em relação à capacidade máxima de água disponível (CAD) no solo, as lâminas aplicadas pelos tratamentos T3 $(535,11 \mathrm{~mm})$, T4 $(609,98 \mathrm{~mm})$ e o T5 $(704,71 \mathrm{~mm})$ favoreceram perfis médios de umidades mais adequados, isto é, sem restrição de umidade ou estresse hídrico prolongado na camada de 0,00-0,40 $\mathrm{m}$, isto é, $400 \mathrm{~mm}$ de profundidade. 




Figura 1- Perfil de distribuição de umidade do solo, média de umidade e CAD na camada de 0,00 $0,40 \mathrm{~m}$ nos tratamentos T1 (i), T2 (ii), T3 (iii), T4 (iv), T5 (v), T6 (vi).

Menzel et al. (1986) explicam que o maracujazeiro amarelo submetido a estresse moderado de umidade por muito tempo, pode limitar sensivelmente o crescimento vegetativo e o potencial produtivo e segundo os autores supracitados o ideal é manter o perfil de umidade do solo próximo da capacidade máxima de água no volume de solo controlado, principalmente no período da floração.

Sousa et al. (2006) verificaram que a aplicação de água entre 709,74 $\mathrm{mm}\left(\mathrm{L}_{2}\right)$ e $944,22 \mathrm{~mm}\left(\mathrm{~L}_{3}\right)$ favoreceu perfis médios de umidade mais adequado na zona radicular do maracujazeiro, enquanto que a aplicação de lâminas de 467,55 $\mathrm{mm}\left(\mathrm{L}_{1}\right)$ e $1178,69 \mathrm{~mm}\left(\mathrm{~L}_{4}\right)$ de água tiveram valores de umidade abaixo e acima do valor referente à capacidade de água disponível no solo, respectivamente.

\section{Características morfofisiológicas de crescimento da planta}

As características morfofisiológicas de crescimento do maracujazeiro amarelo avaliadas foram: área foliar (AF) e o número de folhas (NF). Pela análise de variância (teste F), constatou-se que as lâminas de irrigação influenciaram significativamente: a área foliar $(\mathrm{P}<0,01)$ e número de folhas $(\mathrm{P}<0,05)$. A análise de regressão para a área foliar mostrou efeito linear crescente com o aumento das lâminas de irrigação em quatro épocas de avaliação e mantendo comportamentos semelhantes com bons ajustes.

Observou-se que houve aumento da área foliar com o aumento da quantidade de água aplicada e apresentando menores valores para o tratamento (T1) e maiores valores para tratamento (T6) em todas as épocas avaliadas e esse efeito é explicado por Ball et al. (1994); Benincasa e Leite (2002), em que, o crescimento foliar está em função do requerimento de água, se suprimento de água for inadequado há uma redução no crescimento vegetal, pois o fechamento dos estômatos das folhas reduz a fotossíntese e consequentemente diminui a área foliar, que no caso dos tratamentos $\mathrm{T} 1$ e T2 houveram restrições hídricas no solo. 
Para a característica número de folhas, a análise de regressão revelou efeito significativo e linear crescente em função das lâminas de irrigação.

Somente nos dois períodos finais de avaliações (190 e 210 DAT) é que foi registrado efeito significativo das lâminas de irrigação sobre o número de folhas, comportamento esse que pode ser também atribuído ao fato que o maracujazeiro nessa faixa de idade está em máxima intensidade do seu crescimento vegetativo (MALAVOLTA, 1994), assim como o crescimento da área foliar, o número de folhas também depende do requerimento de água disponível no solo (BENINCASA; LEITE, 2002).

Sousa (2006) realizou avaliações aos 88 e 120 DAT, mas não houve efeitos significativos em função aos diferentes níveis de irrigação sobre esta característica de números de folhas do maracujazeiro amarelo. É importante frisar que é bastante escasso na literatura encontrar informações sobre esta característica de número foliar do maracujazeiro amarelo em função de níveis de irrigação.

\section{Características de produção}

As características de produção do maracujazeiro amarelo avaliadas foram: número de frutos, peso médio de frutos, diâmetro longitudinal e transversal e a produtividade. As avaliações foram realizadas entre o período de 100 a 240 DAT. Pela análise de variância (teste F), constatou-se que as lâminas de irrigação influenciaram significativamente no número de frutos $(\mathrm{P}<0,05)$, peso médio do fruto $(\mathrm{P}<0,05)$ e na produtividade $(\mathrm{P}<0,05)$ conforme os dados da Tabela 2.

Tabela 2 - Síntese da análise de variância do efeito de diferentes lâminas de irrigação nas características de produção do maracujazeiro amarelo, variedade redondo

\begin{tabular}{lccc}
\hline \multirow{2}{*}{ Características de Produção } & \multicolumn{3}{c}{15 de Março a 15 de Maio de 2010} \\
\cline { 2 - 4 } & $\mathrm{R}^{2}$ & CV \% & Média \\
\hline Número de frutos colhidos (unidade) & 0,602 & 16,89 & $29,2^{*}$ \\
Peso médio de frutos $(\mathrm{Kg})$ & 0,643 & 9,61 & $0,186^{*}$ \\
Diâmetro longitudinal $(\mathrm{cm})$ & 0,625 & 25,37 & $55,74^{\text {ns }}$ \\
Diâmetro transversal $(\mathrm{cm})$ & 0,683 & 27,05 & $53,53^{\text {ns }}$ \\
Produtividade $\left(\mathrm{Kg} \mathrm{ha}^{-1}\right)$ & 0,744 & 22,69 & $5384,5^{*}$ \\
\hline
\end{tabular}

ns - não significativo; ** - significância a 1\% ; * significância a $5 \%$.

Para número de frutos do maracujazeiro amarelo a análise de regressão revelou efeito quadrático. O número de frutos aumentou até o seu valor máximo no período de colheita $(33119,5$ frutos $\mathrm{ha}^{-1}$ ) obtido com a aplicação de $763,80 \mathrm{~mm}$ de água, lâmina esta ligeiramente próximo ao equivalente a $120 \%$ da ETo. Manter as plantas com folhas sempre túrgidas é uma característica necessária para a garantia da produção (NOGUEIRA et al., 2001).

A análise de regressão para o peso médio de fruto (PMF) do maracujazeiro amarelo constatouse que o peso médio de frutos aumenta linearmente com a elevação da quantidade de água aplicada. No período avaliado o peso médio do fruto variou de $0,159 \mathrm{~kg}$ para o tratamento $\mathrm{T} 1$ e 0,207 $\mathrm{kg}$ para tratamento T6.

Sousa et al. (2006) registrou peso médio de frutos de maracujazeiro amarelo entre $0,136 \mathrm{~kg}$ e $0,138 \mathrm{~kg}$, estes resultados não foram significativos, isto é, não foram influenciados pelos níveis de irrigação. Os valores de peso médio de frutos registrados neste trabalho $(0,159 \mathrm{~kg}$ e $0,207 \mathrm{~kg})$ foram maiores do que os registrados por Carvalho et al. (2000).

Para a produtividade a análise de regressão mostrou efeito quadrático. A maior produtividade (27052 $\mathrm{kg} \mathrm{ha}^{-1}$ ano $^{-1}$ ) foi obtido com a aplicação de $760,21 \mathrm{~mm}$, lâmina de irrigação próxima ao equivalente a $120 \%$ da ETo. Salienta-se que esta produtividade refere-se apenas 2 meses de colheita.

Rabelo Filho (2006) nas condições de clima e solo do Vale do Curu (CE), irrigando em função do potencial matricial no solo em -0,015, $-0,030$ e -0,070 MPa, aplicou uma lâmina de 184,38 mm, $207,37 \mathrm{~mm}$ e $215,13 \mathrm{~mm}$, respectivamente, porém não houve diferença significativa quanto as lâminas, mas obteve uma variação de $29 \%$ do valor máximo $\left(22790 \mathrm{~kg} \mathrm{ha}^{-1} \mathrm{ano}^{-1}\right)$ e o mínimo (17680 $\mathrm{kg} \mathrm{ha}^{-1} \mathrm{ano}^{-1}$ ).

\section{Evapotranspiração da cultura (ETc) do maracujazeiro amarelo}

A figura 2 ilustra o comportamento da ETo e a ETc em função dos dias após o transplantio da cultura. Verifica-se que, enquanto o maracujazeiro se encontra em desenvolvimento inicial a diferença 
entre a ETo e ETc é relativamente grande, uma vez que a planta encontra-se em pleno desenvolvimento esta diferença diminui com o aumento da massa foliar, principalmente no período de produção em que aparecem os primeiros brotos florais após os 100 DAT, percebe-se também uma crescente diminuição na demanda evaporativa do local a partir de 160 a 210 DAT, mas, com valores médios de ETc sempre muito próximos da ETo, conferindo nestes períodos certo aumento de flores e frutificações. Observa-se que o comportamento da ETc segue o mesmo comportamento da ETo durante o ciclo da cultura.

As variações nos acréscimos dos valores de ETc deveu-se às temperaturas no período do experimento. Visto que, o consumo máximo de água pela planta só ocorre na ausência de restrições hídricas no solo (DOORENBOS; PRUITT, 1977; PEREIRA et al., 1997), condição para o qual é necessário a manutenção dos níveis de umidade do solo sempre próximo ao máximo da capacidade de água disponível no volume de solo controlado (BERNARDO et al., 2009). Porém, nos trabalhos de campo estas boas condições podem ter sido violadas em alguns dias.

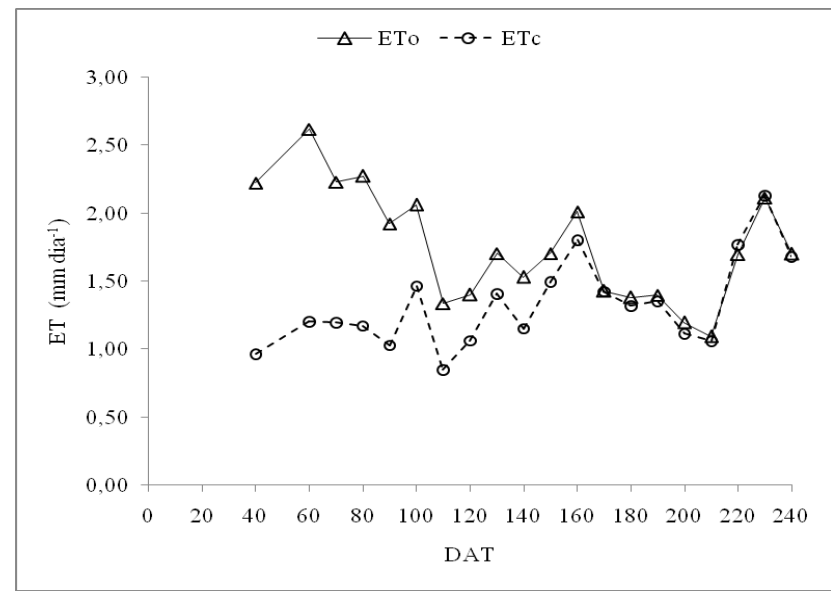

Figura 2 - Comportamento da ETo e ETc durante os dias de avaliação do consumo hídrico da cultura do maracujazeiro amarelo, no município de Santa Rosa do Piauí.

\section{Coeficiente de cultivo (Kc) do maracujazeiro amarelo}

Os valores de coeficiente de cultura foram também determinados durante o período de crescimento até a época ainda inicial de produção (41 - 240 DAT). Normalmente os valores de Kc aumentam, atingem um máximo e depois diminuem em função do ciclo da cultura. Porém neste trabalho acredita-se não ter atingido o máximo valor de Kc, uma vez que as plantas ainda estavam em crescimento. Para o período analisado, em média, os valores de Kc variaram de 0,43 a 1,04 com registro de máximo valor em 211 a 220 DAT (Figura 3).

A partir dos 41 a 90 DAT os valores de coeficientes não apresentaram grandes diferenças devido esta época a área do solo ser pouco coberta pela planta. Aos 91 DAT, observou-se o surgimento de botões florais, houve acréscimo em 0,71 com algumas oscilações, mas sempre em escala crescente. Visto que entre 110 e 130 DAT inicia o surgimento dos primeiros frutos. Pcorre um aumento nos coeficientes a 0,83 , chegando ao 170 DAT com o valor 1,0 no período de início de produção. A partir de então, observou-se um aumento no valores do kc que oscilou entre 1,04, 1,01 e 0,99 dos 200 a 240 DAT. Os acréscimos nos valores de kc são explicados principalmente pelo aumento da área foliar (PEREIRA et al., 1997).

Os valores de kc para a cultura do maracujá observado neste trabalho variaram de 0,43 a 1,04 que não difere muito de Silva et al. (2006), onde encontrou valores de 0,42 a 1,12. Souza (2005) em pesquisa com maracujazeiro da variedade redondo no Vale do Curu (CE), obteve kc entre 0,25 e 1,13. 


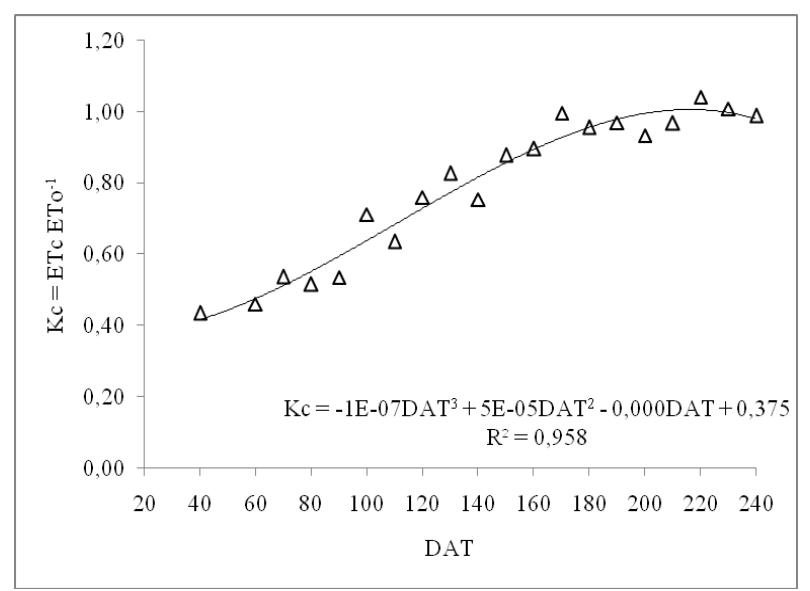

Figura 3- Comportamento do coeficiente de cultivo $(\mathrm{Kc})$ durante os dias de avaliação do consumo hídrico da cultura do maracujazeiro amarelo, no município de Santa Rosa do Piauí.

A oscilações do kc para as mesmas ou diferentes culturas são comuns, pois os valores de kc variam com as características específicas de cada cultura, estádio de desenvolvimento, época de plantio, densidade de plantio, duração da estação de crescimento, condições de umidade e clima (DOORENBOS; PRUITT, 1977). O kc médio obtido para a fase vegetativa foi de 0,57 e para fase de floração 0,94 e 1,04 para a fase de frutificação (Figura 3).

A relação entre os valores médios de Kc encontrados para o maracujazeiro e o número de dias após transplantio (DAT), apresentaram um aumento progressivo e, pelo ajuste da curva de kc, constata-se uma tendência de estabilização a partir dos 220 DAT. De acordo com Haag et al. (1973), na fase de desenvolvimento da cultura, observou-se o acúmulo máximo de área foliar, que ocorre em torno dos 240 DAT. Conforme KOETZ (2006), o índice de área foliar é a principal característica que pode resultar em diferentes valores de coeficiente de cultivo e é o fator biológico mais importante nesse processo, pois representa o tamanho da superfície transpirante.

\section{CONCLUSÕES}

A produtividade do maracujazeiro amarelo, número de frutos e peso médio de frutos são influenciados pela diferenciação de lâminas de irrigação aplicada à cultura.

O maior valor de produtividade, de $27052 \mathrm{~kg} \mathrm{ha}^{-1} \mathrm{ano}^{-1}$, foi obtido com a aplicação máxima de $760,21 \mathrm{~mm}$, com lâmina de irrigação próxima ao equivalente a 1,2* ETo. As lâminas de irrigação mais eficiente para maracujazeiro amarelo se situam entre o equivalente $75 \%$ e $100 \%$ da ETo;

Os valores de coeficiente de cultivo $(\mathrm{kc})$ variaram de 0,43 para a fase vegetativa, 0,94 para fase de florescimento e 1,04 para a fase frutificação.

\section{REFERÊNCIAS BIBLIOGRÁFICAS}

ALLEN, R. G.; PEREIRA, L. S.; RAES, D.; SMITH, M. Crop evapotranspiration - Guidelines for computing crop water requeriments. Rome: FAO, p.308, (FAO Irrigation and Drainage, 56). 1998.

ANUÁRIO DA AGRICULTURA BRASILEIRA - AGRIANUAL. São Paulo: FNP Consultoria e Comércio, 480p. 2013.

ARAÚJO, H. F. de.; COSTA, R. N. T.; CRISÓSTOMO, J. R.; SAUNDERS, L, C. U.; MOREIRA, O. da C.; MACEDO, A. B. M. Produtividade e análise de indicadores técnicos do maracujazeiroamarelo irrigado em diferentes horários. Revista Brasileira de Engenharia Agrícola e Ambiental. Campina Grande, PB, UAEA/UFCG. v.16, n.2, p.159-164. 2012.

BALL, R. A.; OSTERHUIS, D. M. E MAUROMOUSTAKOS, A. Growth dynamics of the cotton plant during water-deficit stress. Agronomy Journal, 86: 788 - 795, 1994. http://dx.doi.org/10.2134/agronj1994.00021962008600050008x

BENINCASA, M. M. P.; LEITE, I. C. Fisiologia vegetal. Jaboticabal: Funep, 2002. p. 169.

BERNARDO, S.; SOARES, A. A.; MANTOVANI, E. C. Manual de irrigação. 8 ed.Viçosa: Ed. UFV, 625p. 2009. 
BEZERRA, M. V. C.; SILVA, B. B. da.; BEZERRA, B. G.; BORGES, V. P.; OLIVEIRA, A. S. de. Evapotranspiração e coeficiente de cultura do algodoeiro irrigado a partir de imagens de sensores orbitais. Revista Ciência Agronômica. v. 43, n. 1, p. 64-71, jan-mar, 2012. http://dx.doi.org/10.1590/S1806-66902012000100008

CARVALHO, A. J. C. de; MARTINS, D. P.; MONNERAT, P. H.; BERNARDO, S. Adubação nitrogenada e irrigação no maracujazeiro amarelo. I. produtividade e qualidade dos frutos. Pesquisa Agropecuária Brasileira, Brasília, v. 35, n. 6, p. 1101-1108, jun. 2000. http://dx.doi.org/10.1590/S0100-204X2000000600005

DOOREMBOS, J.; PRUIT, J. O. Guidelnes for predicting crop water requirements. Rome: FAO (Irrigation and Drainage Paper, 24), 179 p. 1977.

DOURADO NETO, D.; NIELSEN, D. R.; HOPANS, J. W.; PARLANGE, M. B. Programa SWRC (Version 3.0): Soil-Water Retention Curve (Software). Piracicaba: ESALQ; Davis: University of Califórnia, 2 disquetes. 1995.

EMBRAPA. Catálogo de fruticultura: cultivares da Embrapa 2010. Brasília. (Embrapa Transferência de Tecnologia), 50 p. 2010.

FREIRE, J. L. de O.; CAVAlCANTE, L. F.; REBEQUI, A. M.; DIAS, T. J.; NUNES, J. C.; CAVALCANTE, Í. H. L. Atributos qualitativos do maracujá-amarelo produzido com água salina, biofertilizante e cobertura morta no solo. Revista Brasileira de Ciências Agrárias. v. 05, n. 01, p. 102-110, 2010. http://dx.doi.org/10.5039/agraria.v5i1a674

HAAG, H. P.; OLIVEIRA, G. D.; BORDUCHI, A. S.; SARRUGE, J. R. Absorção de nutrientes por duas variedades de maracujá. Anais da Escola Superior de Agricultura Luiz de Queiroz, Piracicaba, v. 30, p. 267-279, 1973.

IBGE-INSTITUTO BRASILEIRO DE GEOGRAFIA E ESTATÍSTICA. Ministério do Planejamento, Orçamento e Gestão. ISSN 0101-3963. Produção Agrícola Municipal: Culturas temporárias e permanentes. Rio de Janeiro, v. 37, p.1-91, 2010.

KOETZ, M. Maracujazeiro-amarelo: cultivo protegido e natural, irrigação e adubação potássica . 119 p. Tese (Doutorado em Irrigação e Drenagem) - Universidade Federal de Lavras, Lavras. 2006.

MALAVOLTA, E. Nutricion y fertilizacion del maracuya. Piracicaba: CENA: USP, 52-53 p. 1994.

MENZEL, C. M; SIMPSON, D. R; PRINCE, G. H. Effect of foliar applied nitrogen during winter on growth, nitrogen content and production of passionfruit. Scientia Horticulturae, Amsterdam. v.28, p.339-346, 1986. http://dx.doi.org/10.1016/0304-4238(86)90108-1

MELETTI, L. M. M.; OLIVEIRA, J. C.; RUGGIERO, C. Maracujá. Jaboticabal: FUNEP, (Série Frutas Nativas, 6.). 2010.

MOROKE, T. S.; SCHWARTZ, R. C.; BROWN, K. W.; JUO, A. S. R. Water use efficiency of dryland cowpea, sorghum and sunflower under reduced tillage. Soil \& Tillage Research, v.112, p.76-84, 2011. http://dx.doi.org/10.1016/j.still.2010.11.008

NOGUEIRA, R. J. M. C.; MORAES de, J. A. P. V.; BURITY, H. A.; NETO, E. B. Alterações na resistência à difusão de vapor das folhas e relações hídricas em aceroleiras submetidas a déficit de água. Revista Brasileira de Fisiologia Vegetal, 13 (1): p. 75-87, 2001. http://dx.doi.org/10.1590/S0103-31312001000100009

PAES, H. M. F.; ESTEVES, B. dos S.; SOUSA, E. F. de. Determinação da demanda hídrica do quiabeiro em Campos dos Goytacazes, RJ. Revista Ciência Agronômica. v. 43, n. 2, p. 256-261, abr-jun, 2012. http://dx.doi.org/10.1590/S1806-66902012000200007

PEREIRA, L. S.; ALLEN, R. G. Novas aproximações aos coeficientes culturais. Engenharia Agrícola, Jaboticabal, v. 16, n. 4, p. 118 - 143, 1997.

RABELO FILHO, M. A. Aspectos produtivos do maracujazeiro amarelo submetido à irrigação e adubação potássica. Fortaleza, 2006, 89 f. Dissertação (Mestrado em Irrigação e Drenagem). Universidade Federal do Ceará, 2006.

SANTOS, W. V.; RESENDE, P. L. Produção de Maracujá: série fruticultura. Viçosa-MG: CPT, 172 p. 2006.

SILVA, T. J. A. da; FOLEGATTI, M. V.; SILVA, C. R. da; ALVES JÚNIOR, J.; PIRES, R. C. de M. Evapotranspiração e coeficientes de cultura do maracujazeiro amarelo conduzido sob duas orientações de plantio. Irriga, Botucatu-SP. v. 11, n. 1, p. 90-106, jan/mar, 2006. 
SILVA, T. G. F. da.; MOURA, M. S. B. de.; ZOLNIER, S.; SOARES, J. M.; VIEIRA, V. J. de S.; JÚNIOR, W G. F. Requerimento hídrico e coeficiente de cultura da cana-de-açúcar irrigada no semiárido brasileiro. Revista Brasileira de Engenharia Agrícola e Ambiental. v.16, n.1, p.64-71, 2012.

SOUSA, V. F. de; FOLEGATTI, M. V., FRIZZONE, J. A; CORRÊA, R. A. de L.; VIANA, T. V. A. Produtividade do maracujazeiro amarelo sob diferentes níveis de irrigação e doses de potássio via fertirrigação. Engenharia Agrícola, Jaboticabal, v.26, n.2, p. 365-373, maio/ago. 2006.

SOUZA, M. do S. M. de, Evapotranspiração e coeficientes de cultivo do maracujá em duas tensões da água no solo. Fortaleza, 2005, 94 f. Dissertação (Mestrado em Irrigação e Drenagem). Universidade Federal do Ceará, 2005.

VAN GENUTCHEN, M. T. H. A closed-from equation for predicting the hydraulic conductivity of insatured. Soil Science Society American Journal, Madison, v. 41, p. 892 - 898, 1980. http://dx.doi.org/10.2136/sssaj1980.03615995004400050002x

VERMEIREN, L.; JOBLING, G. A. Irrigação localizada. Campina Grande. (Estudos FAO: Irrigação e Drenagem, 36), p. 184. 1997.

VIANA, P. C.; LIMA, J. G. A.; ALVINO, F. C. G.; JUNIOR, J. R. de S.; GOMES, É. C.; VIANA, K. C. Efeito da salinidade da água de irrigação na produção de maracujazeiro-amarelo. Revista Agropecuária Científica no Semiárido. v. 8, n. 1, p. 45-50, jan-mar, 2012. 